\title{
A comicidade como possibilidade criativa na dança contemporânea
}

ANA CAROLINA MUNDIM

Atriz, bailarina, fotógrafa e pesquisadora das artes do corpo. Bacharel e Licenciada em Dança, Mestre e Doutora em Artes pela Universidade Estadual de Campinas (UNICAMP) e pela Universitat Autónoma de Barcelona. Atualmente é professora adjunta efetiva do Curso de Dança da Universidade Federal de Uberlândia. Desde 2009 desenvolve a pesquisa Dramaturgia do corpo-espaço e territorialidade, que faz conexões entre as áreas de física mecânica, arquitetura, dança, teatro e música, objetivando a criação em dança pautada na improvisação e na composição em tempo real. Desde 2010 a pesquisa está vinculada ao seu projeto docente, desenvolvido junto à Universidade Federal de Uberlândia, que inclui grupo de pesquisa de mesmo título, o grupo de estudos Corpo e Expressividade e o Conectivo Nozes. E-mail: mundim.ana@gmail.com 


\section{- RESUMO}

O presente artigo busca discutir a comicidade como possibilidade criativa na dança contemporânea, pensando-a como processo de manifestação corpórea. Criando diálogo com artistas que produzem trabalhos bem humorados, identificamos alguns pontos convergentes e divergentes nas escolhas realizadas e nos modos de acionar a comicidade na cena. Apontamos, ainda, como a comicidade pode ser discutida em um campo mais amplo, para além do entretenimento, podendo se articular como instrumento de poder, como veículo de provocação e/ ou de reflexão e/ou como ótica de ação em relação ao mundo.

\section{- PALAVRAS-ChAVE}

Dança contemporânea, comicidade, criação.

\section{- ABSTRACT}

This article discusses the comicality as a creative possibility in contemporary dance, thinking about it as a body manifestation process. Creating a dialogue with artists who produce amused works, we have identified some converging and some diverging points between the choices made and the ways to put comicality in scene. We have also considered how comicality can be discussed in a larger field, not only as entertainment, but also articulating itself as an instrument of power, as a vehicle of incitement and/or reflection and/or as a point of view in relation to the world.

\section{- KEYWORDS}

Contemporary dance, comicality, creation.

As ideias de riso e comicidade, embora percorram um amplo campo de atuação, frequentemente são associadas, dentro do universo cênico, à comédia enquanto gênero teatral. No dicionário etimológico da língua portuguesa (DA CUNHA, 2007, p. 198), a palavra cômico é relacionada à comédia, ao ridículo, ao burlesco, àquilo que faz rir. E a comédia, por sua vez, é definida "como obra ou representação teatral em que predominam a sátira e a graça" (Idem, Ibidem).

Pensar na comicidade enquanto gênero, no entanto, não será tarefa do presente texto. Propomos uma perspectiva que localize a comicidade em um universo mais amplo, menos encerrado em expectativas e, portanto, mais repleto de nuances. Desse prisma, a comicidade não se dá necessariamente como um dado a priori, como um ponto de partida para um processo criativo; ela ocorre enquanto processo e como ação manifesta do corpo. Parece-nos que é nesse lugar que a dança contemporânea abraça a comicidade de modo recorrente. Apesar das abordagens cênicas que transitam entre as áreas de Dança e Teatro serem cada vez mais comuns, entendemos que há especificidades nos modos de aproximação desses distintos campos de conhecimento em relação ao humor. Sobre essas distinções, Dudude Hermann, bailarina e coreógrafa mineira, considera:

A maioria dos espetáculos teatrais que vejo estão ligados na espécie humana, o humano, o corpo social, o personagem, o texto falado, a história, os pecados capitais, as virtudes. $\mathrm{O}$ teatro ronda e se apoia no homem e faz para o outro homem. Isto é o que observo e sinto. Não vejo problema nisso, é uma prática. Em dança podemos criar espetáculos, usando da linguagem da improvisação pensando apenas nas intensidades, nos volumes, e tendo como parceiro tudo que ali está, seja a luz, a 
parede, a roupa, as cores, o desejo de ser atravessado pelo espaço, de ser afetado pela intensidade, e assim nos permitindo a ser coisa também. Tudo fala, o espaço fala, tudo é importante, trabalhamos para estar na mesma frequência e assim imagens poderosas se apresentam no momento $X$ do acontecimento. Isto me tem interessado cada vez. Ver o visível no invisível, tornar a ser "algo", criar campos de sensibilidades compartilhadas com o outro e deixar um estado de arte ser desvelado".

A partir desse prisma, a comicidade que se pretende na dança, portanto, parte da corporalidade e de tudo que a afeta e que é por ela afetado. Compreender como o corpo cria e transcria essas vivências encarnadas, impregnadas, por meio de seus humores em movimento, é dialogar com o universo da dança. Como aborda Tuca Pinheiro, bailarino e coreógrafo mineiro:

No campo das artes cênicas é importante entender as especificidades de cada área. $\mathrm{O}$ teatro tem suas especificidades, o circo, e também a dança. Acredito que uma das especificidades da dança é abordar questões através de uma partitura corporal. Nossa partitura é o corpo - que abriga e ao mesmo tempo revela e traduz seu pensamento. Entender o humor na dança é entendê-lo a partir do corpo, como esse corpo traduz seu pensamento através da dança sob a ótica do humor.

Pensar no humor, dentro de uma dramaturgia de dança, é pensar na necessidade dele (do humor) enquanto elemento não dissociado dos outros materiais envolvidos na organização coreográfica. O humor na dança não é o conceito, é o corpo².

Nos ateremos neste texto, portanto, a experiências em dança que atuam como provocadoras de risos (por vezes incômodos), por meio de suas partituras corporais. Essas experiências, porém, são diversas em seus percursos, em suas opções estéticas e em suas proposições cênicas. O riso pode ser sutil ou rasgado, pode questionar, salientar, contradizer, refazer, alienar, encantar, desagradar. Jorge Alencar, diretor do grupo baiano Dimenti, conhecido por seus trabalhos irreverentes, comenta em seu artigo "Dança contemporânea e a comicidade" (2008), publicado no site idança.net:

Ao invés de me deter na estóica missão de indagar "o que é o riso" ou "quais são os métodos infalíveis de fabricação do cômico na dança", procuro pensar de que maneira essa reflexão pode corroborar na afirmação do corpo em suas dimensões performativa e pedagógica e do cômico como um meio de subversão de poder e estereótipos. O foco, então, deixa de ser a produção de uma gargalhada explosiva, ou a restrita associação entre riso, bem-estar e prazer. Nesse caminho, o cômico deixa ainda de ser entendido como um mero elemento ou um estilo de criar. Em sua agenda performativa, a comicidade na dança contemporânea ganha o direito de ser, inclusive, desagradável, alcançando uma inflexão mais ampla e produtiva do discurso do corpo (ALENCAR, 2008).

A produção de discursos corporais que destrinchem o bom humor como matéria de expressão pode gerar estados no intérprete e no público, que estejam muito além do

\footnotetext{
1 Dudude Hermann em entrevista para a autora deste artigo, em março de 2013.

2 Tuca Pinheiro em entrevista para a autora deste artigo em março de 2013. 
desejo inicial do riso em si. Em alguns momentos, o riso se dá como única alternativa possível para lidar com a reelaboração cênica de aspectos ásperos e/ou até mesmo indigestos do cotidiano. Encontrar o bom humor na corporalidade permite por vezes um estado crítico, e por vezes, cítrico, de um riso duro que atravessa a si e ao outro.

Dudude Hermann, com frequência, apresenta em seus trabalhos boas doses de humor que revelam reflexões acerca da condição humana. No espetáculo A Projetista, por exemplo, ela compartilha com o público a crueza dos sistemas de editais de financiamento no Brasil e as práticas constantes de escrita de projetos, gerando inúmeras distorções na vida profissional diária de um artista. Expondo e ampliando a situação a que nós, bailarinos, nos sujeitamos nas tentativas constantes de provar a relevância de nossa profissão aos agentes financiadores e à sociedade, Dudude provoca risos que rasgam o espaço-tempo da apresentação e ecoam no repensar sobre as práticas cotidianas.

Sobre seus processos de criação, a bailarina diz:

Não tenho interesse algum antes do processo de cada trabalho que faço. O processo de qualquer dos trabalhos que fiz vai se apresentando e por uma escolha subjetiva e sutil vamos temperando o trabalho com estados que se tornam essenciais, uma aventura com certeza. Se caso apareça uma cena bem humorada e ela torne-se vital para o trabalho, aceitamos. Quando inicio o trabalho não sei exatamente o que será, e assim não parto de um determinado desejo... "quero fazer algo engraçado..." Quando uma ideia me visita, primeiro escuto seu desejo de vir a ser e as demandas que se apresentam.

Não penso a partir do humor, ou da tragédia. Vou como um detetive farejando o que precisa ser experimentado e qual o tom de cada cena. Pode ser que me considere uma pessoa "bem humorada", e algo de mim possa contaminar a cena em si e, talvez, a primeira vista possa aparecer humorado, engraçado, mas tudo é muito sério e está valendo. Vale dizer sobre a qualidade dos risos de cada espetáculo: às vezes nervosos, às vezes estridentes, às vezes como uma maneira de fugir, etc.

Acredito que o humor possa ser mais difícil e complexo do que a tragédia em si. Certamente tenho e nutro preferências por um humor ácido, atrevido, idiossincrático, que talvez possa ser outra coisa, IRONIA. Gosto de assistir trabalhos onde o irônico a primeira vista parece ser uma graça, um estado bem humorado e que possui volume para que o espectador possa adentrar cada vez mais ${ }^{3}$.

Dudude fala do humor, citando algumas perspectivas reacionais possíveis. A partir delas, podemos identificar situações de catarse, fuga e incômodo. A catarse ocorre como forma de libertação das amarras cotidianas e de dar vazão aos prazeres, em um ato pontual que excede as práticas comuns da moralização social. Por um lado, essa pode ser uma prática isolada vinculada ao gozo e ao êxtase, configurando-se como ato em si. Por outro, pode ser um potente instrumento de poder, por parte de quem a proporciona, uma vez que, por vezes, ela promove estados alterados de consciência e pode, inclusive, gerar alienação ou fuga. Entender a dança nesse contexto, em algumas situações, significa associar a produção de comicidade

3 Dudude Hermann em entrevista para a autora deste artigo em março de 2013. 
em movimento a estruturas de manobra política que se apropriam do fazer artístico para manipular situações ou estados que favoreçam os interesses e a manutenção das estruturas de poder. Exemplos disso são a sempre atual Política do Pão e Circo, os eventos populistas, os showmícios, entre outras práticas políticas, em que se pensa no riso e na arte como entretenimento e como modo de alienação política e social.

A dança, historicamente, sempre esteve sujeita a processos de manipulação política, tendo como fortes referências a serem lembradas o período dos balés de corte, na França, as danças que reiteravam o nazismo, na Alemanha ou aquelas que sublinhavam a ditadura, no Brasil. Os balés de corte, com seu surgimento datado de 1581 , foram criados como parte do divertimento da corte e, por isso, eram chamados de divertissement. Totalmente vinculados às festas, numa imbricação político-social tinham como objetivo principal cultuar a figura do rei. Jean-Georges Noverre, no século XVIII, propõe a defesa do balé de ação, o qual considera oposto ao balé de corte. Para Noverre (Idem, Ibidem, p. 46) o "[...] divertissement se assemelha aos fogos de artifício, que se limitam a agradar os olhos, uma forma vazia, desprovida de qualquer caráter de expressão." É interessante pensarmos na ação do movimento como oposição à manipulação do movimento. Noverre compõe o balé por meio da pantomima, como visibilidade das ações e propõe a imaginação como expressão dos sentimentos. Para Noverre (MONTEIRO, 1998, p. 162), a pantomima aproxima o bailarino do comediante, pois como ele "[... ] sai dos limites estreitos da arte e procura torná-lo mais esclarecido (éclaire). Volta-se para a literatura, para a poesia e para a história, amplia os horizontes, cultiva-se, vai além da 'superfície das coisas'."

A passagem entre o balé de corte e o balé de ação, portanto, começa a redimensionar os modos de atuação da dança na relação com a comicidade e com a ótica por meio da qual se produz o humor e o movimento. Noverre (Idem, Ibidem, p. 164) dizia que o bailarino deveria tornar-se comediante sem deixar de ser bailarino. É fundamental ressaltar que, para ele, a ideia do bailarino no balé de corte estava muito vinculada à atuação técnica e mecânica de movimentos. Já no balé de ação, a busca era por um intérprete que fosse capaz de demonstrar, além de sua atuação técnica precisa, uma capacidade de expressão artística, manifestando sentimentos e relacionando sua prática cênica à intelectualidade e à criticidade dos seus pensamentos.

Noverre, portanto, teve papel fundamental na história da dança, revolucionando a visão sobre o intérprete e seu posicionamento no processo criativo, o que reverbera até hoje nas ações em dança. Apesar de inúmeros acontecimentos históricos após o século XVIII, que perpetuaram a dança como possibilidade de manipulação política, assim com os já citados casos do nazismo alemão e da ditadura brasileira, uma grande parte das práticas contemporâneas que se estabelecem cenicamente reforçam a necessidade de se acionar uma comicidade muito mais próxima do discurso provocativo do que do estado de graça. Nesse sentido, é imprescindível refletirmos sobre uma comicidade na dança que, como disse Dudude Hermann, é levada a sério, ou como apontou Jorge Alencar, está para além da gargalhada explosiva ou da simples relação comumente estabelecida entre riso, bem-estar e prazer.

Levar o humor a sério... Redimensionar o uso do humor, tornando-o discurso e não pretexto, é deslocar o riso de uma resposta automatizada à piada e transcender a ideia da comicidade como passatempo. João Francisco Duarte Junior (2010, p. 52) diz: 
[...] levar o humor a sério não é uma contradição que temos, mas uma atitude completamente coerente de quem acredita que o riso seja dimensão fundamental da existência humana, gerando alegria, aliviando tensões e, sobretudo, produzindo uma relação lúdica e sensível com as coisas, a qual permite que sejam essas coisas apreendidas e aprendidas em sua leveza e beleza constituintes (DUARTE JUNIOR, 2010, p. 52).

Relacionar-se com o humor como um mergulho que permite a profundidade de um encontro consigo próprio e com o movimento criativo, pode ser o princípio de uma ação senão transformadora, minimamente questionadora. Lidar com o lúdico e a sensibilidade e apreender o entorno através da leveza acionam a poesia como centro articulador das relações humanas e das práticas artísticas. Nesse sentido, a comicidade proporciona novos sentidos e/ou até soluções para zonas de turbulência e tração. No texto "O corpo real-ficcional ou o corpo carnavalizado na dança cênica" (2012, p. 267), já discutíamos, a partir de uma consideração de Jorge Larrosa, como os riscos provocados pelo riso nos retiram de uma zona de conforto e nos permitem adentrar em nós mesmos a partir da provocação que nos traz. Por considerarmos relevante o pensamento do autor sobre esta questão, tornamos a citá-lo:

O riso destrói as certezas. E especialmente aquela certeza que constitui a consciência enclausurada: a certeza de si. Mas só na perda da certeza, no permanente questionamento da certeza, na distância irônica da certeza, está a possibilidade do devir. O riso permite que o espírito alce vôo sobre si mesmo. O chapéu de guizos tem asas.

E não venham vocês me dizer que o riso é perigoso. O riso é, certamente, ambíguo e perigoso. Como os livros, como as viagens, como os jogos, como o vinho, como o amor. Como tudo que tem valor, o riso não é diferente da ambiguidade radical de qualquer experiência de formação, pelo menos quando a formação é concebida de uma forma por demais harmoniosa, por demais construtiva, por demais linear, por demais edificante. Na formação existe, às vezes, tensão, destruição, negação. [...] E se o riso é perigoso, talvez o que ocorra é, simplesmente, que só na prova do perigo pode estar a verdadeira salvação. Não a salvação entendida como uma saída de emergência ou como uma reclusão perpétua em um lugar protegido, mas a salvação da própria vida. E um pensamento que não seja capaz de enfrentar o mundo e de enfrentar-se a si mesmo, com um chapéu de guizos, talvez seja um pensamento que está a salvo (LARROSA, 2006, p. 181).

Identificamos, assim, o riso como possibilidade para enxergar a seriedade da vida, não necessariamente negando a seriedade, mas encontrando um novo modo de dialogar com ela. Significa encontrar no riso uma prática de se arriscar em vida, de se mover, de se enveredar pela poesia no fazer diário e em sua potencialização cênica que assiste ao cotidiano de modo reflexivo e amplia seus sentidos na relação com o entorno. Encontrar a seriedade do riso pode ser uma chave para uma nova prática artística e social. Jorge Larrosa considera:

O riso polemiza com o sério, entra em contato com o sério, dialoga com o sério, com essa linguagem elevada que pretende envolver o mundo e compreendê-lo e 
dominá-lo, com essa linguagem canonizada e aceita que não duvida de si mesma. O riso desmascara a linguagem, retira-a de seu lugar, de seus esconderijos, a expõe ao olhar como ela é, como uma casca vazia. [...].

[...] quando entra o riso o diálogo é diferente. Quando aparece o riso, objetiva-se o universo ideológico, a linguagem, a situação comunicacional, o plano (ideológico, linguístico, social) em que o diálogo sério é possível (LARROSA, 2006, p. 178-179).

Criar relações dialógicas pelo humor dilui as certezas absolutas, relativizando parâmetros e colocando em questão o previsível. O riso desconcerta, desestabiliza, propõe, chacoalha qualquer iniciativa de fixidez dos pensamentos/ações. Ele retira a sisudez da seriedade, sem necessariamente se desconectar da seriedade. Em seu livro A montanha e o videogame, João Francisco Duarte-Júnior aborda:

Roberto Gomes fala em "sério" e em "a sério", e a transformação do adjetivo ("sério") numa locução adverbial de modo ("a sério") pela simples inclusão da preposição "a" faz uma brutal diferença $[\ldots]$

Ocorre que levar alguma coisa a sério tem a ver com a atitude em relação a ela, com o valor que ela tem em nossa vida, ao passo que a expressão "homem sério" frequentemente conduz a um estereótipo, desde os trajes que ele veste até as palavras que emprega, ou seja, o rigor com que assume certos "figurinos". Nesse sentido, quem toma algo a sério na verdade o encara com o rigor dedicado a questões vitais, ao passo que os comportamentos estereotipados que definem o indivíduo dito sério têm muito mais a ver com o rigor mortis de que falam os legistas ao examinar um cadáver - endurecimento de um corpo sem vida (DUARTE JUNIOR, 2010, p. 51).

João Francisco, assim como Jorge Alencar, ressalta a relevância de se transcender os estereótipos. Os estereótipos, tanto do homem sério quanto do homem divertido ou do espetáculo sério e do espetáculo divertido, formatam de um modo rígido as leituras possíveis a serem realizadas sobre a pessoa ou sobre o ato artístico. Os estereótipos organizam-se praticamente como funções que geram respostas esperadas e preestabelecem imagens, solidificando-as. Talvez seja nesse sentido que João Francisco traga a perspectiva de que um corpo estereotipado como sério seja um corpo sem vida. A seriedade em relação a um assunto não está na forma em que este assunto se apresenta, mas na condução dos atos. E quando conduzido por meio da comicidade, o assunto tende à flexibilização, e não ao engessamento. Como diz Jorge Alencar: "O humor muitas vezes é uma experiência de acidente e até de incongruência, quando as coisas são arranjadas fora de seu padrão usual, propondo novos nexos" ". Há um grande nível de imprevisibilidade nas soluções propostas pelo humor.

Para Abbagnano (2007, p. 179), a comicidade é: "O que provoca o riso, ou a possibilidade de provocá-lo, através da resolução imprevista de uma tensão ou de um conflito." A partir dessa definição, se pensarmos no conflito ou na tensão como pontos de ruptura e/ou fissura, podemos compreender que se irrompe dessa ação uma possibilidade de criação de um estado provocativo, propositivo. Nessa fissura

4 Jorge Alencar em entrevista para a autora deste artigo em março de 2013. 
propõe-se a poética, nesse lugar de inspiração (fisiológica e criativa) desbloqueiam-se as fricções e se encontra espaço para rir de si mesmo, do outro, das situações. Neste momento, se pode construir um riso de alívio, de prazer, de solidariedade, de indagação, de nervoso, de incômodo, de afeição, de gozação. Qual riso se deseja? Qual riso se manifesta?

Tratar da comicidade, desse modo, significa expandir as capacidades de abordagem criativa e entender sua ação em um âmbito mais flexível do que determinante. Para Jorge Alencar:

Coreografar numa dimensão humorística para mim tem a ver com compor de um jeito em que as ideias se coloquem em risco e com flexibilidade. Tem uma série de mecanismos de comicidade que poderiam ser listados como a ironia, o exagero, o contraste, a repetição, entre outros, mas mais do que um arranjo desses mecanismos, para mim, tem a ver com uma percepção mais geral, que certamente é algo mais aberto e que não dá para listar com exatidão.

Acho que nem seria o caso de dizer que "eu uso" o humor porque, para mim, a coisa é menos ferramenta ou ingrediente e mais algo que constitui profundamente aquilo que eu faço. Nem sei como me reconhecer fora disso que me interessa porque me surpreende, me confunde, me causa estranhamentos e me deixa arreganhado a novas percepções de mundo, de mim e do outro.

Mesmo quando, na criação coreográfica, eu não pretendo provocar o riso necessariamente, eu faço questão de estar no mundo e na dança com humor. Isso tem a ver com um sentido de abertura, de inusitado, de delírio, de prazer ${ }^{5}$.

Essa fala de Jorge parece destacar uma questão fundamental, já levantada neste texto pelo depoimento de Dudude Hermann, que diz respeito à criação coreográfica como derivação de uma visão de mundo por parte do artista. Esta questão é muito nítida quando Bobby Baker, artista visual e cênica, fala sobre o uso do humor em seu trabalho:

O humor é parte central em minha obra, porque penso que es uma das formas com que me comunico. La questão é que me é muito difícil tomar decisões sobre os temas com os quais trabalho e, por meio do humor, posso fazê-los entrar em conflito sem que as decisões pareçam demasiado drásticas. Algumas vezes a gente resiste a participar e seguir o discurso dos espetáculos, então é quando o humor atua como meio para fazer com que as ideias fluam e penetrem na atitude desse público. É una forma muito subversiva e reveladora de introduzir a informação. Fazer algo divertido sobre algo é fazer algo divertido de mim mesma. Posso ver una ideia desde distintas perspectivas e desde distintas emoções concretas, porém tudo isso se conecta através do humor. É como fazer um embrulho da obra no qual a cobertura ou envoltório é o humor. É também uma forma de enviar ideias a outras pessoas que nunca as entenderiam de outra forma. Quando comecei a trabalhar como artista de ação me enfadava muitíssimo comigo porque eu queria ser uma artista seria. Ao fi-

\footnotetext{
5 Idem.
} 
nal, sempre acabava fazendo rir e rindo-me eu mesma, não podia resistir-me; então compreendi que era um meio muito eficaz para comunicar-me. Provenho de una geração de mulheres que utilizaram o humor como uma forma de sobrevivência, é um meio de provocação para fazer-se presente no mundo. (SANCHES e CONDE-SALAZAR, 2003, p. 125) ${ }^{6}$

É possível notar que Bobby tinha uma necessidade de produzir em cena algo que se deslocava de sua natureza como artista, pois de certa forma, seu pensamento era permeado pela ideia estereotipada de que o artista sério não lida com o riso. Sua atitude criativa se alterou apenas quando ela conseguiu reconhecer no riso um caminho para discutir questões que lhe pareciam relevante e posicionar-se diante delas.

O coreógrafo, em seu processo criativo, não está desconectado do modo como se posiciona em sua vida cotidiana. A criação potencializa a ação cotidiana e traz para a cena questões a serem discutidas, de modo intencional, organizadas a partir de uma poética. Assim, é possível identificar que, de um modo geral, a opção pela comicidade na construção de um trabalho na dança se dá, menos pela preocupação com o gênero e mais em decorrência do modo como coreógrafo ou os intérprete-criadores lidam com as situações propostas no processo criativo.

Milena Figueiredo, bailarina e coreógrafa de Campinas, reforça esta questão ao comentar sobre o trabalho do Grupo das Excaravelhas, do qual faz parte:

O Grupo das Excaravelhas sempre criou os espetáculos coletivamente e a partir dos desejos / ânsias artísticas de cada integrante. E em cada uma de nós, o humor é um elemento presente no cotidiano e em cada encontro. Nosso interesse em usar o humor surgiu espontaneamente durante o processo de convivência dentro e fora da sala de ensaio.

A partir da estrutura da composição iniciamos o processo de pesquisa de movimentação e cenas, e os elementos de humor vão surgindo através dos movimentos e ideias que temos durante o próprio processo. O humor, muitas vezes, não é pensado previamente, mas aparece nas improvisações e podemos utilizá-lo ou não.

Pode-se usar o humor como crítica ou simplesmente como uma situação cênica sem esse preceito?.

\footnotetext{
6 No original: "El humor es parte central en mi obra, porque pienso que es una de las formas en que me comunico. La cuestión es que me resulta muy difícil tomar decisiones sobre los temas con los que trabajo y a través del humor puedo hacerlos entrar en conflicto sin que las decisiones parezcan demasiado drásticas. Algunas veces la gente se resiste a participar y seguir el discurso de los espectáculos, entonces es cuando el humor actúa como medio para hacer que las ideias fluyan y penetren en la actitud de ese público. Es una forma muy subversiva y reveladora de introducir la información. Hacer algo divertido sobre algo es hacer algo divertido de mí misma. Puedo ver una ideia desde distintas perspectivas y desde distintas emociones concretas, pero todo ello se conecta a través del humor. Es como hacer un paquete de la obra en el que la cubierta o el envoltorio es el humor. Es también una forma de enviar ideas a otra gente que nunca las entenderían de otra forma. Cuando empezé a trabajar como artista de acción me enfadaba muchíssimo comigo porque yo quería ser una artista seria. Al final siempre acababa haciendo reír y riéndome yo misma, no podía resistirme; entonces comprendí que era un medio muy eficaz para comunicarme. Provengo de una generación de mujeres que han utilizado el humor como una forma de supervivencia, es un medio de provocación para hacerse presentes en el mundo." (SANCHES e CONDE-SALAZAR, 2003, p. 125)

7 Milena Figueiredo em entrevista para a autora deste artigo em março de 2013. 
Notamos, portanto, que não parece ser uma preocupação tão potente na criação cômica em dança o estudo de dispositivos técnicos que acionem o riso, como ocorre por exemplo nos estudos de clown ou na Commedia dell'Arte. Em alguns casos há coreógrafos que buscam mecanismos para orientar o trabalho de composição, como comenta Holly Cravell, bailarina e coreógrafa americana, radicada no Brasil, e diretora da Cia Domínio Público, de Campinas:

Acho que a dança deriva seu humor a partir do uso específico dos elementos do timing, foco e percepção das diferentes qualidades e dinâmicas. A manipulação dessas ajudam a criar as circunstâncias combinadas que resultam em situações intencionais ou não intencionais de humor ${ }^{8}$.

No entanto, esses elementos não se aplicam como protocolos de criação a serem generalizados. Tampouco há uma fórmula ou receita de composição cênica que se relacione às práticas cômicas na dança. $O$ riso pode se dar de diversos modos: pelo seu esgarçamento (riso escancarado), pela sua sutileza, pela sua acidez, pela sua ironia, pela demarcação de território ou até mesmo disfarçado nas entrelinhas, entre outros. E também são distintas as maneiras de colocar o corpo em experiência de modo que produza o riso.

A ironia, porém, aparece como um mecanismo que recorrentemente desperta interesse na dança contemporânea. Holly Cravell, por exemplo, quando questionada sobre seu interesse em utilizar humor nos trabalhos, responde: "É a forma irônica que me ajuda tratar de um tema ou questões sérias e humanas". Para Jorge Larrosa:

A polêmica em torno da ironia expressa o contraste entre uma ideia de formação não abandonada, que destaque os momentos dinâmicos da não satisfação (do rompimento, do ceticismo, da contradição, do paradoxo, da desilusão, da antítese, da finitude, da insuficiência, do devir, do relativo, da dissonância, da irregularidade, da decepção), e uma ideia mais dogmática, mais construtiva, mais fechada, mais edificante, que tende a uma determinação, a uma solidificação final da subjetividade e do caráter, a um acabamento no processo de formação. A ironia expressa uma forma de consciência etérea, que paira sobre tudo, e que em nada se fixa porque não pode tomar partido a partir de uma situação particular frente a outra situação. A ironia provém da unilateralidade, da determinação da fixação. Por outro lado, a ironia também é, talvez de modo fundamental, a auto-ironia. Na consciência irônica o eu está sempre por cima de si mesmo e por isso não toma, a si mesmo, muito a sério. A consciência irônica é uma consciência em que o eu sempre está se revelando frente ao seu próprio poder, frente a qualquer instalação satisfeita pelo seu próprio sucesso, frente a qualquer fixação. $O$ irônico pode ser impertinente porque, em primeiro lugar, o é consigo mesmo. Resumindo, o irônico seria aquele que se põe, em si mesmo, o chapéu de guizos sempre que o mundo se faz demasiadamente compacto e sempre que sua própria subjetividade se faz demasiadamente consistente e ameaça colocar-se excessivamente de acordo consigo mesma. Frente à estatuária, o chapéu de guizos permite que entre a leve fluidez da música para que a dança volte a começar (LARROSA, 2006, p. 173-174).

8 Holly Cravell em entrevista para a autora deste artigo em março de 2013. 
A ironia, portanto, traz movimento constante às relações. Revestida de uma sagacidade potente, incorre no risco de tornar-se instrumento de poder, de um processo hierárquico em que aquele que provoca a ironia se localiza em uma zona de superioridade em relação àquele ou àquilo que é zombado. Porém, se acionada também como auto-ironia, transgride e subverte as expectativas, pois desfaz as estruturas relacionais convencionais e suprime eixos paradigmáticos. A ironia diz o desdito e desdiz o dito. Bobby Baker, artista visual e cênica, considera:

A ironia é algo muito complicado e complexo de explicar. É algo assim como dizer de uma forma graciosa algo que é o contrário do que queres dizer. Cresci em uma escola na qual o sarcasmo era a base da educação. Entendi que nunca podias dizer o que realmente querias dizer e sim o contrário. (SANCHES e CONDE-SALAZAR, 2003, p. 126) ${ }^{9}$

A ironia pressupõe adentrar em paradoxos, em contradições, expor incoerências, mover o que está por baixo da superfície, rever conceitos. Não é o lugar da calmaria ou do conformismo, mas precisa cuidar-se para não se tornar autoritária. A ironia atiça os sentidos e a percepção na medida em que encarna a aguçada intelectualidade e procura a troca com o outro.

É buscando em cena um jogo de identificação com o público que o artista encontra seu par na leve dança proposta e o convida a mergulhar no universo criativo ali compartilhado. Dessa forma se fazem possíveis as conexões da produção artística que perpassam aspectos das relações estabelecidas entre criador e espectador. Para Tuca Pinheiro:

Todo processo criativo tem em si a assinatura biográfica de quem o faz - sua forma de ver e entender o mundo. Mas entendo que o biográfico, o subjetivo, no processo criativo, é uma ferramenta. Não um fim em si mesmo. Entendo o biográfico como uma plataforma para se chegar ao universal, ao coletivo. O humor enquanto crítica social está vinculado a essa forma de ver e entender o mundo (arquivos) - daquele que cria e daqueles que compartilham o resultado de tal criação (os arquivos nem sempre são os mesmos). Por isso em alguns momentos o humor pode sim atuar enquanto crítica social (quando os arquivos são compreensíveis e dialogam - os arquivos de quem cria e os arquivos de quem tem acesso ao resultado da criação). Outra coisa a se considerar é a contextualização/descontextualização do humor (corpo-ideia/material). Ou seja, a capacidade de observação para transitar com esse corpo/humor (do subjetivo para o coletivo) dentro da composição coreográfi$\mathrm{ca}$, atento a organização das ideias ${ }^{10}$.

Tuca coloca em discussão que o humor também depende dos processos de recepção por parte do público. Há um conjunto de fatores que colaboram para que o riso seja ou não acionado, e eles estão diretamente vinculados ao modo como cada um se

\footnotetext{
9 No original: "La ironía es algo muy complicado y complejo de explicar. Es algo así como decir de una forma graciosa algo que es lo contrario de lo que quieres decir. Crecí en una escuela en la que el sarcasmo era la base de la educación. Entendí que nunca podías decir lo que realmente querías decir sino lo contrario." (SANCHES e CONDE-SALAZAR, 2003, p. 126)

10 Tuca Pinheiro em entrevista para a autora deste artigo em março de 2013. 
aproxima da experiência de fruição artística, às suas identificações com o tipo de humor acionado e às suas referências sobre as questões abordadas. É no corpo a corpo que se dá o riso na dança, ou seja, na compreensão do estado vivificado da presença.

\section{Conclusões}

Independente dos processos escolhidos por coreógrafos e intérprete-criadores para produção de trabalhos artísticos, identificamos que, majoritariamente, as conexões estabelecidas entre a comicidade e a dança contemporânea se dão por arquivos mnemônicos destes artistas, os quais produzem modos específicos de lidar com o mundo a partir de uma visão bem humorada. A discussão em foco normalmente não é a comicidade em si. A comicidade, frequentemente, é a trajetória natural de abordagem de um determinado assunto. No ofício da composição, no entanto, é preciso ter a sapiência de quando o humor pode contribuir para o trabalho de criação. Como aponta Tuca Pinheiro sobre suas próprias seleções de composição:

Os processos criativos, e seus consequentes resultados (independentes da natureza desse resultado - texto, vídeo, coreografia, performance etc...) estão fortemente conectados aos arquivos pessoais (questões artísticas e existenciais dos criadores). Esses mesmos arquivos são organizados a partir de escolhas, organização, e da capacidade de observação do cotidiano que está a sua volta. Minhas questões artísticas e minhas questões de existência se confundem e ao mesmo tempo se completam, alimentando uma a outra. O humor sempre esteve presente nesses arquivos. Daí, o interesse na forma de abordar essas questões, ou traduzir fisicamente esses arquivos, através do humor, como consequência, para usá-lo, quando necessário, como ponte, como ferramenta, como possibilidade, desde que necessário (não é um recurso a priori). Particularmente, gosto de fazer distinção entre fazer humor e fazer graça. O humor em si não me interessa. Me interessa o corpo que é capaz de decodificar suas questões (artísticas e existenciais) fazendo uso do humor.

Eu não penso a composição coreográfica a partir do humor. Para mim a composição coreográfica é resultado de uma organização de ideias (materiais). Ideias (materiais coletados durante o processo criativo) que, quando colocadas umas ao lado das outras, elas se completam. Elas têm a mesma fala. Não são dissonantes. Faço uso do humor (enquanto corpo), quando surge como material (ideia) e não está dissonante ao que está sendo discutido ${ }^{11}$.

O depoimento de Tuca converge com as já citadas falas de Dudude Hermann, Jorge Alencar, Bobby Baker, Holly Cravell e Milena Figueiredo sobre os seus processos criativos: a comicidade é criada como consequência de uma relação desses artistas com seu entorno. Quando os resultados artísticos incluem o bom humor, isso ocorre como reverberação do percurso de composição e a partir de uma opção consciente vinculada ao assunto em questão.

A comicidade na dança contemporânea, então, só carrega uma certeza: a produção de humor a partir do próprio corpo, manifestado em si próprio ou nas relações que ele cria.

\footnotetext{
11 Idem.
} 


\section{Referências}

ABBAGNANO, Nicola. Dicionário de filosofia. São Paulo: Martins Fontes, 2007.

ALENCAR, Jorge. Dança contemporânea e comicidade. Http://idanca.net/lang/pt-br/2008/06/18/danca-contemporanea-e-comicidade/6071. Acesso em: 18 mar. 2013.

DA CUNHA, Antônio Geraldo. Dicionário etimológico da língua portuguesa. Rio de Janeiro: Lexikon Editora digital, 2007.

JÚNIOR, João Francisco Duarte. A montanha e o videogame: escritos sobre educação. Campinas, SP: Papirus, 2010.

LARROSA, Jorge. Pedagogia profana: danças, piruetas e mascaradas. Belo Horizonte: Autêntica, 2006.

MONTEIRO, Marianna. Noverre: cartas sobre a dança. São Paulo: Editora da Universidade de São Paulo: FAPESP, 1998.

MUNDIM, Ana Carolina. O corpo real-ficcional ou o corpo carnavalizado na dança cênica. In: BRONDANI, Joice Aglae; LEITE, Vilma Campos; TELLES, Narciso. Teatro-máscara-ritual. Campinas, SP: Editora Alínea, 2012.

SÁNCHEZ, José A; CONDE-SALAZAR, Jaime. Cuerpos sobre blanco. Cuenca: Ediciones de la Universidad de Castilla - La Mancha: Comunidad de Madrid, 2003. 